\title{
Analysis of green liquor influence on coal steam gasification process
}

\author{
Mateusz Karczewski ${ }^{1,}{ }^{*}$, Stanisław Porada $^{1}$ \\ ${ }^{1}$ AGH University of Science and Technology, Faculty of Energy and Fuels, al. Mickiewicza 30, \\ 30-059 Cracow, Poland
}

\begin{abstract}
Gasification is a clean and efficient technology with a long history dating up to the $19^{\text {th }}$ century. The possible application of this process ranges from gas production and chemical synthesis to the energy sector and therefore this technology holds noticeable potential for future applications. In order to advance it, a new efficient approaches for this complex process are necessary. Among possible methods, a process enhancing additives, such as alkali and alkaline earth metals seems to be a promising way of achieving such a goal, but in practice might turn to be a wasteful approach for metal economy, especially in large scale production. This paper shows alkali abundant waste material that are green liquor dregs as a viable substitute. Green liquor dregs is a waste material known for its low potential as a fuel, when used separately, due to its low organic content, but its high ash content that is also abundant in alkali and alkaline earth elements seems to make it a suitable candidate for application in coal gasification processes. The aim of this work is an evaluation of the suitability of green liquor waste to work as a potential process enhancing additive for coal steam gasification process. During the experiment, three blends of hard coal and green liquor dregs were selected, with consideration for low corrosive potential and possibly high catalytic activity. The mixtures were gasified in steam under four different temperatures. Their energies syngas yield, coal conversion degree and energies of activation were calculated with use of Random Pore Model (RPM) and Grain Model (GM) which allowed for their comparison.
\end{abstract}

\section{Introduction}

Among various methods of coal processing, gasification is already renowned technology with background reaching back to $19^{\text {th }}$ century. Its biggest past application was town gas production from coal but was later replaced by the use of natural gas. Recently, as a clean process with extensive potential in both energy and chemical industry, the interest in this technology increased as a part of the search for sustainable and more efficient ways of energy production. To this day, a large variety of aspects were analyzed i.e. use of different operating conditions, agents and solid fuel types being the most popular [1-5].

One of more interesting aspects of this research is process enhancement by use of catalytic materials. Their addition is reported to change the kinetics of gasification process and lower

\footnotetext{
*Corresponding author: mateusz.karczewski@agh.edu.pl
} 
its activation energy. To date, several works already stated the positive effects of various additives on process rate and/or syngas composition [6-8] with alkali and alkaline earth metals being the most popular due to lower price in comparison with other catalysts such as iron [9] or noble metals [10] and their high process efficiency enhancement [11-13].

On the contrary, a certain amount of issues may arise if such approaches were applied to industrial-scale activities. For example, wet impregnation of coal with material mixing and drying might prove to be too complex for implementation in larger installations, despite ensuring high catalyst-fuel contact [14], leaving physical mixing as only viable approach [15]. The other issue is the need of use of market alkali or alkaline compounds which might be a wasteful approach for the metal economy, especially in large scale production. The solution for this problem might be the utilization of waste materials with a high abundance of alkali and alkaline earth metals, such as green liquor dregs.

Green liquor dregs are Kraft paper mill side product with ash composition containing slightly different content that can be found in typical ashes derived from combustion processes. Its mineral composition is based mostly on potassium, magnesium, calcium, manganese abundant [16] wood ash and iron (if wood is recycled) with the highest presence of calcium originating process of caustization that uses lime for spent solvent recovery. Another source of active material in the waste is solvent itself that consist mostly of sodium sulfate for lignin breakdown [17]. As a result, green liquor dregs are a partially carbonaceous material with high mineral content rich in various alkali components. This kind of waste product can find its use as cheap catalyst material that can process together with fuel in order to utilize the catalytic potential of its mineral constituents with the additional conversion of its carbon content.

Therefore the aim of this work is an evaluation of green liquor wastes as a possible catalytic additive for coal steam gasification process as a material abundant in the potentially process enhancing components. The content of materials has been analyzed in order to determine proper waste and coal fuel blends for further research. The mixtures were steam gasified with coal in four temperatures. Their kinetic parameters were calculated basing on several kinetic models i.e. Random Pore Model (RPM) and Grain Model (GM) which allow for their comparison along with syngas yield and coal conversion degree.

\section{Material and method}

\subsection{Material preparation}

The experiment was performed with coal obtained from Szczygłowice mine and green liquor waste received from one of Polish paper mills. Both coal and green liquor were air-dried until a stable weight was obtained and then ground in ring roller mill (EKOLAB LAB-09-200). The resulting powders were the sifted for fractions under $0.2 \mathrm{~mm}$ in diameter.

\subsection{Elemental and Technical Analysis}

The measurements of elemental composition were conducted with Eltra CHS-580 analyzer, with accordance to polish standardized laboratory procedures $[18,19]$. The measurement provided information on carbon and hydrogen content but also allowed for sulfur measurement.

The proximate analysis comprised of moisture, volatile matter and ash content and the lower heating value was also performed in order to obtain data for indices calculations. Moisture, volatile matter and ash analysis were performed with a thermogravimetric analyzer (Eltra Thermostep) and the lower heating value was measured with a bomb calorimeter 
Table 1. Ultimate and proximate analysis of used hard coal and green liquor waste.

\begin{tabular}{|c|c|c|}
\hline Proximate analysis & Coal & $\begin{array}{c}\text { Green } \\
\text { Liquor }\end{array}$ \\
\hline Moisture - $\mathrm{M}^{\mathrm{a}}[\% \mathrm{wt}]$ & 1.8 & 4.4 \\
\hline Ash $-A^{a}[\% w t]$ & 7.7 & 56.0 \\
\hline Volatile matter - VM ${ }^{\mathrm{daf}}[\% \mathrm{wt}]$ & 25.0 & 29.9 \\
\hline Lower Heating Value - LHV ${ }^{\mathrm{daf}}[\mathrm{kJ} / \mathrm{kg}]$ & 33247 & 5477 \\
\hline Ultimate analysis & Coal & $\begin{array}{c}\text { Green } \\
\text { Liquor }\end{array}$ \\
\hline Carbon - $\mathrm{C}^{\mathrm{daf}}[\% \mathrm{wt}]$ & 88.8 & 55.4 \\
\hline Hydrogen - $\mathrm{H}^{\mathrm{daf}}[\% \mathrm{wt}]$ & 5.21 & 2.92 \\
\hline Sulfur - Sdaf $[\% \mathrm{wt}]$ & 0.46 & 0.63 \\
\hline Oxygen\&Nitrogen - O+N${ }^{*}[\% \mathrm{wt}]$ & 5.54 & 41.09 \\
\hline
\end{tabular}

(Leco AC 350), according to the polish standards [20,21]. Table 1 present all results from proximate and ultimate analysis.

Both materials were also characterized for their ash composition which was determined by X-ray fluorescence using EDXRF spectrometer (Panalytical Epsilon ${ }^{3 \mathrm{XLE}}$ ). For later calculations, the resulting ash elemental content was assumed to be present only in the form of oxides and therefore its content was recalculated to include oxygen presence and adjusted to $100 \%$. Resulted oxides ash concentration was shown in Table 2.

Table 2. Characteristic of green liquor and hard coal ash constituents.

\begin{tabular}{|l|cc|}
\hline Ash constituent & Coal [wt\%] & Green Liquor [wt\%] \\
\hline $\mathrm{MgO}$ & 17.24 & 3.28 \\
$\mathrm{Na}_{2} \mathrm{O}$ & 11.72 & 2.77 \\
$\mathrm{~K}_{2} \mathrm{O}$ & 2.09 & 4.29 \\
$\mathrm{Fe}_{2} \mathrm{O}_{3}$ & 3.70 & 7.96 \\
$\mathrm{SiO}_{2}$ & 3.14 & 38.69 \\
$\mathrm{Al}_{2} \mathrm{O}_{3}$ & 1.33 & 29.30 \\
$\mathrm{CaO}$ & 49.65 & 6.53 \\
$\mathrm{P}_{2} \mathrm{O}_{5}$ & 0.59 & 2.35 \\
$\mathrm{TiO}_{2}$ & 0.02 & 1.35 \\
$\mathrm{Cl}$ & 0.22 & - \\
\hline
\end{tabular}




\subsection{Determination of fuel blends composition}

With data on fuel elemental composition, potential blend weight ratios were estimated with the corrosive potential of resulting fuel as main quality. To achieve this, several indices aimed at corrosion prediction presented elsewhere [16] were calculated for various amount of waste addition. From the results, an index with the lowest tolerance for the waste addition was chosen as the general limit for green liquor addition. Out of analyzed indices, $\mathrm{Cl}$ ratio and $\mathrm{S}$ ratio, presented below, provided the lowest waste addition limits:

$$
\begin{gathered}
\text { Cl ratio }=\frac{\%\left(\mathrm{Cl}+\mathrm{K}_{2} \mathrm{O}+\mathrm{Na}_{2} \mathrm{O}\right)}{\%\left(\mathrm{SiO}_{2}+\mathrm{Al}_{2} \mathrm{O}_{3}\right)} \\
\text { S ratio }=\frac{\%\left(\mathrm{~S}+\mathrm{K}_{2} \mathrm{O}+\mathrm{Na}_{2} \mathrm{O}\right)}{\%\left(\mathrm{SiO}_{2}+\mathrm{Al}_{2} \mathrm{O}_{3}\right)}
\end{gathered}
$$

Where compound name states the content by weight of the corresponding compound. The results have shown that the presence of slight slagging, achievable for $\mathrm{Cl}$ ratio above 1 and for $\mathrm{S}$ ratio above 0,5 [16] suggested potential slight slagging presence at $23 \%$ and $63 \%$ of waste addition, respectively. As the calorific value of green liquor waste is rather low, the lower amount was chosen for further blends preparations in order to keep fuel blend quality.

For further evaluation, catalytic properties were also taken into account. Therefore four blends with the addition of $5,10,15$ and $20 \%$ of green liquor waste were prepared in order to cover the whole range of established green liquor addition margin with the addition of (from now on also named as GL5, GL10, GL15 and GL20 blends, respectively) by weight were analyzed for their content of potentially enhancing elements, as shown in Table 3. For the sake of comparison, additional sample of untreated Szczygłowice hard coal was also used (named as Coal from now on).

Table 3. Elements in ashes of analyzed fuel blends and coal used in the experiment with potential catalytic influence.

\begin{tabular}{|c|c|c|c|c|c|}
\hline \multicolumn{6}{|c|}{ Elemental content in fuel mixture [wt\%] } \\
\hline & Coal & GL5 & GL10 & GL15 & GL20 \\
\hline $\mathrm{Mg}$ & 2.61 & 3.07 & 3.53 & 3.99 & 4.46 \\
$\mathrm{Na}$ & 2.20 & 2.66 & 3.12 & 3.59 & 4.05 \\
$\mathrm{~K}$ & 3.40 & 3.86 & 4.33 & 4.79 & 5.25 \\
$\mathrm{Fe}$ & 6.32 & 6.78 & 7.25 & 7.71 & 8.17 \\
$\mathrm{Ca}$ & 5.19 & 5.65 & 6.11 & 6.57 & 7.04 \\
$\mathrm{Mn}$ & 0.14 & 0.60 & 0.51 & 0.70 & 0.88 \\
\hline
\end{tabular}

Table 3 shows that analyzed elements only occur in certain, relatively small quantities in resulting blends despite their large concentration in waste material. Most of the alkali materials appear in a range between 3 and 5\% with more abundant in given materials elements like $\mathrm{Fe}$ and $\mathrm{Ca}$ appeared in quantities between 5 and $7 \%$. According to recent advances in catalytic additives $[23,24]$ the amount around $3.40 \%$ for $\mathrm{Na}$ and $\mathrm{K}$ and around $5 \%$ for $\mathrm{Ca}[24]$ are very favourable, therefore the fuel blends consisting of amounts up to $15 \%$.seems to have the best catalytic potential, suggesting use of the samples with $5 \%, 10 \%$ and $15 \%$ waste addition for further experiment. 


\subsection{Steam gasification}

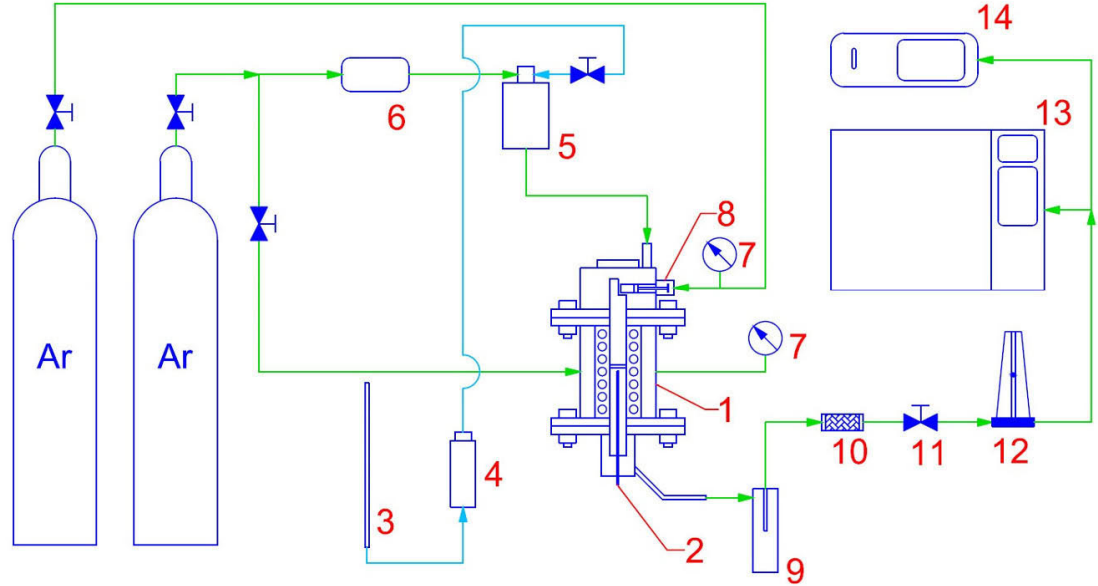

Fig. 1. The laboratory equipment for kinetics examinations of coal steam gasification process. 1 - reactor, 2 - thermocouple, 3 - water tank, 4 - water pump, 5 - steam generator, 6 - mass flowmeter, 7- pressure gauge, 8 - biomass feeder, 9 - cooler, 10 - filter, 11 - pressure regulator, 12-rotameter, 13 - gas chromatograph, $14-\mathrm{CH}_{4}, \mathrm{CO}, \mathrm{CO}_{2} \mathrm{IR}$ analyser.

Measurement of the gasification process along with kinetics determination was carried out with the use of the system shown in Figure 1. The process applied elevated pressure of 11 bars with isothermal conditions carried out at four temperatures: $850,900,950$ and $1000^{\circ} \mathrm{C}$ and with controlled sample injection. This system was already successfully used in other gasification kinetic measurements [24,25]. In resulting syngas flow, the content of methane, carbon monoxide and carbon monoxide was continuously controlled by a gas analyzer (Fuji Infrared Gas Analyzer) utilizing infrared radiation adsorption for concentration determination. The content of hydrogen was analyzed using gas chromatograph (HP 5890) equipped with thermal conductivity detector (TCD). The details on methane, carbon monoxide, and carbon dioxide concentrations in flue gas allowed for calculation of changes in formation rates for measured process gasses as a function of time. Such data was used for composition and conversion degree determination by calculating the yield of each product from the area under curve $\mathrm{dV} / \mathrm{dt}=\mathrm{f}(\mathrm{t})$. The carbon conversion degree was also evaluated with use of the volume of carbon-based gaseous products with given equation:

$$
X(t)=\frac{\left(V_{c o}(t)+V_{C O 2}(t)+V_{C H 4}(t)\right) M_{C}}{V_{m o l} m C^{d a f}} 100 \%
$$

where:

$V_{\mathrm{CO}}(t), V_{\mathrm{CO} 2}(t), V_{\mathrm{CH} 4}(t)$ - volume of released gas component at standard conditions as a function of time, $\mathrm{dm}^{3} / \mathrm{g}$

$V_{\text {mol }}$ - volume of one mole of gas at temperature of $273 \mathrm{~K}$ and pressure of $101325 \mathrm{~Pa}, \mathrm{dm}^{3} / \mathrm{mol}$ $\mathrm{M}_{\mathrm{c}}$ - molar mass of carbon, $\mathrm{g} / \mathrm{mol}$

$\mathrm{m}$ - sample mass, $\mathrm{g}$

$C^{\text {daf }}$ - dry ash free carbon content, -

In order to determine the activation energy Grain Model (GM) and Random Pore Model (RPM) [26] were used as models suitable for gas-solid heterogeneous reactions. The GM and RPM models are described by equations (2) and (3), respectively. 


$$
\begin{gathered}
\frac{\mathrm{dX}}{\mathrm{dt}}=\mathrm{k}_{\mathrm{GM}}(1 \quad \mathrm{X})^{\frac{2}{3}} \\
\frac{\mathrm{dX}}{\mathrm{dt}}=\mathrm{k}_{\mathrm{RPM}}\left(\begin{array}{llll}
1 & \mathrm{X}) \sqrt{1} \quad \Psi \ln (1 \quad \mathrm{X})
\end{array}\right.
\end{gathered}
$$

where:

$\mathrm{k}_{\mathrm{X}}$ - pre-exponential factor for given model, $1 / \mathrm{s}$

$\Psi$ - parameter is associated with the pore structure of the test material, due to nature of the process set at 2 .

\section{Results and discussion}

The degree of carbon conversion, calculated according to equation (1), from gas products for every fuel blend in various temperatures was presented in Table 4. Starting from the lowest temperature of $850^{\circ} \mathrm{C}$ for gasification, fuel reaches the lowest conversion rates of $43.6 \%$ for pure coal sample and rises noticeably with the addition of green liquor to $67,71.1$ and $71.2 \%$ for blend GL5, GL10 and GL15, respectively. The carbon conversion increased with the rise of reaction temperature, achieving rates between 51.9 and 79.8 for $900^{\circ} \mathrm{C}, 56.7$ to 90.4 for $950^{\circ} \mathrm{C}$ and 59.4 to 99.7 for $100^{\circ} \mathrm{C}$. The lowest conversion rates in all analyzed temperatures were obtained for gasification of Coal, while GL10 blend has achieved the best results in every given temperature with a slight drop in conversion with the bigger addition of waste in the GL15 blend and even lower rates when lowest waste addition in GL5 blend was used.

Table 4. Total carbon conversion degree calculated with respect to gas products.

\begin{tabular}{|c|c|c|c|c|}
\hline \multicolumn{5}{|c|}{ Carbon to syngas conversion [wt\%] } \\
\hline RT $\left[{ }^{\mathbf{}} \mathbf{C}\right]$ & Coal & GL5 & GL10 & GL15 \\
\hline $\mathbf{1 0 0 0}$ & 59.4 & 92.4 & 99.7 & 94.8 \\
$\mathbf{9 5 0}$ & 56.7 & 85.7 & 90.4 & 88.1 \\
$\mathbf{9 0 0}$ & 51.9 & 74.3 & 79.8 & 78.9 \\
$\mathbf{8 5 0}$ & 43.6 & 67 & 71.1 & 71.2 \\
\hline
\end{tabular}

$\mathrm{RT}$ - reaction temperature $\left[{ }^{\circ} \mathbf{C}\right]$

The results are complemented by syngas compounds total production, presented in Table 5. They show that addition of green liquor has a noticeable influence on every syngas constituent. Methane concentrations increased with the biggest effect in GL10 blend, where the yield of $\mathrm{CH}_{4}$ increased from 18 for coal up to $34 \mathrm{~cm}^{3} / \mathrm{g}$ in the case of lowest temperature and doubled from 32 to $65 \mathrm{~cm}^{3} / \mathrm{g}$ when the highest temperature of $1000^{\circ} \mathrm{C}$ was used. The increase of methane content hints that catalytic properties of green liquor might enhance not only gasification process but also the pyrolysis as methane production only occurs during initial contact of fuel with heat that is later followed by proper reaction with the gasifying medium. The analogical increase occurred in hydrogen and carbon monoxide yields, where GL10 blend increased hydrogen production from 1294 to $1557 \mathrm{~cm}^{3} / \mathrm{g}$ for $850^{\circ} \mathrm{C}$ and from 1693 up to 2123 for $1000^{\circ} \mathrm{C}$. Analogical yield for carbon monoxide accounts for an increase from 276 up to $609 \mathrm{~cm}^{3} / \mathrm{g}$ and from 509 up to $902 \mathrm{~cm}^{3} / \mathrm{g}$, respectively. The only syngas constituent not following the trend is carbon dioxide that keeps relatively constant yield 
between temperatures for every blend with a minor increase when the temperature is lower, but followed by decrease when a low temperature of $850^{\circ} \mathrm{C}$ is achieved, possibly due to the low conversion of fuel. What is more, $\mathrm{CO}_{2}$ shows the highest yield increase for GL5 blend instead of GL10. The GL5 blend achieved a $\mathrm{CO}_{2}$ yield in the range of 516-637 $\mathrm{cm}^{3} / \mathrm{g}$ in comparison with $368-425 \mathrm{~cm}^{3} / \mathrm{g}$ yield for coal. As GL5 blend seems to give the lowest increase in other syngas constituents out of all fuel mixtures, this effect might be caused by low contact of enhancing elements with coal particles.

Table 5. Total amount of gas product obtained from given fuel blend in given temperature, expressed as $\mathrm{cm}^{3} / \mathrm{g}$

\begin{tabular}{|c|c|c|c|c|c|}
\hline \multirow[t]{2}{*}{ Sample } & \multirow{2}{*}{$\begin{array}{c}\text { Temperature } \\
{\left[{ }^{\circ} \mathrm{C}\right]}\end{array}$} & \multicolumn{4}{|c|}{ Syngas Yield $\left[\mathrm{cm}^{3} / \mathrm{g}\right]$} \\
\hline & & $\mathrm{CO}$ & $\mathrm{H}_{2}$ & $\mathrm{CO}_{2}$ & $\mathrm{CH}_{4}$ \\
\hline \multirow[t]{4}{*}{ Coal: } & 850 & 276 & 1294 & 368 & 18 \\
\hline & 900 & 333 & 1490 & 425 & 30 \\
\hline & 950 & 427 & 1574 & 400 & 33 \\
\hline & 1000 & 509 & 1693 & 376 & 32 \\
\hline \multirow[t]{4}{*}{ GL5 } & 850 & 473 & 1438 & 516 & 23 \\
\hline & 900 & 539 & 1598 & 553 & 31 \\
\hline & 950 & 650 & 1629 & 615 & 30 \\
\hline & 1000 & 672 & 2006 & 637 & 37 \\
\hline \multirow[t]{4}{*}{ GL10 } & 850 & 609 & 1557 & 425 & 34 \\
\hline & 900 & 688 & 1712 & 470 & 48 \\
\hline & 950 & 801 & 1942 & 515 & 49 \\
\hline & 1000 & 902 & 2123 & 455 & 65 \\
\hline \multirow[t]{4}{*}{ GL15 } & 850 & 506 & 1502 & 546 & 22 \\
\hline & 900 & 615 & 1671 & 543 & 34 \\
\hline & 950 & 740 & 1882 & 545 & 45 \\
\hline & 1000 & 742 & 2084 & 501 & 51 \\
\hline
\end{tabular}

Based on results of syngas yields, the best sample for calorific gas production was chosen and its process of production was compared in respect of hydrogen and carbon dioxide production with that of coal (Fig. 2 and Fig. 3).

Analysis of hydrogen production during gasification process (Fig 2) revealed several changes that occurred when green liquor additive was used. The first influence can be seen during pyrolysis step where a rapid increase of production was visibly enhanced. Moreover, the drop in hydrogen rate of formation occurred with almost instant stabilization of hydrogen production after pyrolysis step ended whereas additive-free ended its pyrolysis step by a stronger drop in hydrogen rate of formation followed by rate of formation increase that marked the beginning of fuel-steam reactions. This might suggest that green liquor constituents either enhanced bond breaking inside of coal structure and steam to dissociate into hydrogen or caused gasification process to occur along with pyrolysis. The temperature also plays an important role during gasification of both coal and fuel blends as it causes much higher fuel depletion that leads to a decrease of reaction time with the increase of gasification temperature. 


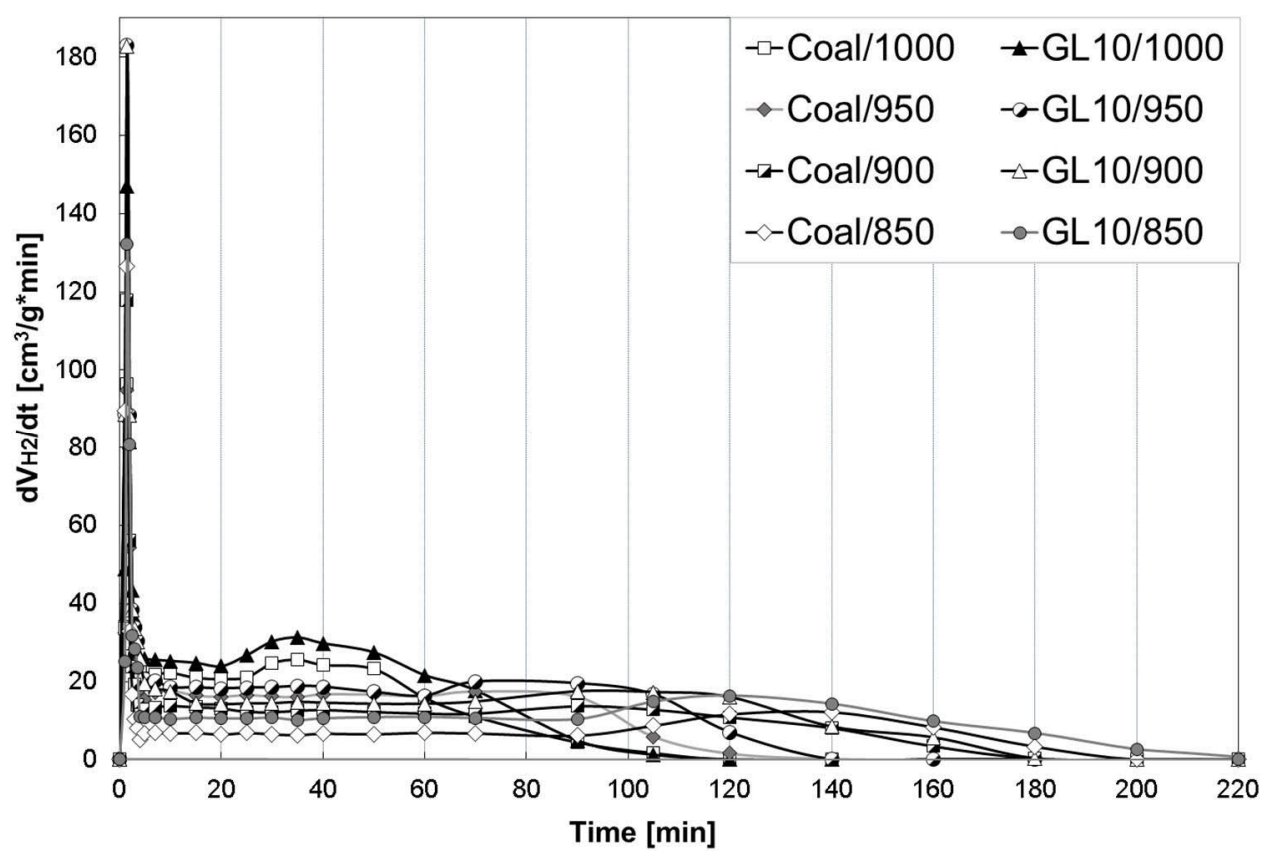

Fig. 2. Influence of green liquor addition on the kinetics of hydrogen production in comparison with untreated coal sample.

Analysis of gas production behavior for carbon monoxide (Fig 3) revealed the analogical effect of increased gas production and smoothening of pyrolytic products formation rate drop. When comparing the duration of gasification step between carbon monoxide and hydrogen it can be also noticed that carbon monoxide drop in rate of formation occurs slightly

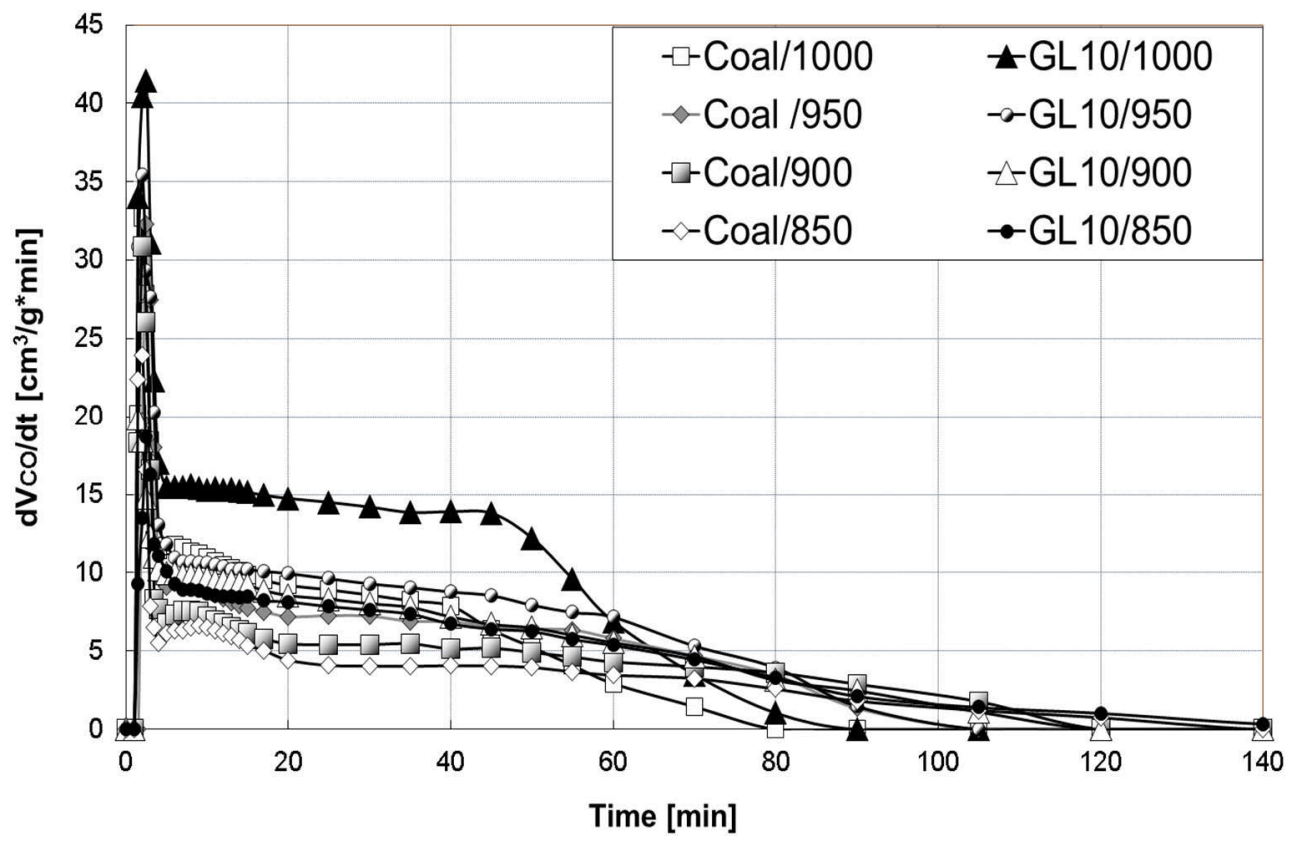

Fig. 3. Influence of green liquor addition on the kinetics of carbon monoxide production in comparison with untreated coal sample. 
before hydrogen rate of formation drop and it is not followed by a visible increase of rate of formation before the drop, unlike hydrogen. The source of hydrogen increase might suggest that with depletion of sample steam began to react with produced carbon monoxide, resulting in syngas production consisting almost only of carbon dioxide and hydrogen at the end of the process. As in the case of both coal and coal with green liquor, the resulting moments where reaction ended were very similar, it can be assumed that addition of green liquor had minimal influence on this step of gasification.

Table 6. The activation energy for steam gasification process for coal and fuel blends calculated with use of Random Pore Model and Grain Model.

\begin{tabular}{|c|c|c|c|c|c|c|c|c|}
\hline & \multicolumn{2}{|c}{ Coal } & \multicolumn{2}{c|}{ GL5 } & \multicolumn{2}{c|}{ GL10 } & \multicolumn{2}{c|}{ GL15 } \\
\cline { 2 - 8 } & RPM & GM & RPM & GM & RPM & GM & RPM & GM \\
\cline { 1 - 6 } $\mathbf{E}_{\mathbf{a}}[\mathbf{k J} / \mathbf{m o l}]$ & 48.1 & 49.7 & 42.8 & 42.5 & 38.5 & 38.2 & 39.6 & 38.8 \\
\cline { 1 - 4 } $\mathbf{k}_{\mathbf{0}}[\mathbf{1} / \mathbf{s}]$ & 0.109 & 0.104 & 0.0122 & 0.0120 & 0.0135 & 0.0136 & 0.0131 & 0.0134 \\
\hline
\end{tabular}

Grain Model and Random Pore Model were used to calculate activation energy for every blend used in the experiment, basing on data from four different temperature measurement applied. The results were shown in Table 6 . The results show that addition of green liquor to coal influenced not only syngas yield and conversion rates, but also decreased the energy of activation. The calculated values for both models ranged from $48.1 \mathrm{~kJ} / \mathrm{mol}$ for RPM and 49.7 for GM obtained for untreated coal to activation energies of 42.8 to 38.5 range for RPM and 42.5 to $38.2 \mathrm{~kJ} / \mathrm{mol}$ range for GM with the lowest energy of activation achieved at GL10 blend. Those values point that addition of green liquor allowed the process to utilize the presence of green liquor constituents to use the different mechanism with lower energy of activation. Moreover the results for different amounts of green liquor additives shown that such mechanism can efficiently work only for limited ash composition, as fuel with $15 \%$ of green liquor addition has shown slightly worse results than fuel blend with $5 \%$ lower waste content, suggesting that mechanism of the process is heavily influenced by contact between fuel and active components of green liquor.

\section{Conclusions}

The use of green liquor waste as a catalytic additive for coal gasification in steam seem to be a viable option for process enhancement. The blended mixture prepared based on information obtained from corrosion indices and existing research allowed for the determination of waste addition suitable for process enhancement with potentially low adverse effect on used installation.

The results of steam gasification have shown that the best blend out of analyzed waste:coal ratios in fuel is $10 \%$ by weight of green liquor addition. This mixture allowed for the heavy jump in the degree of carbon conversion, up to $99.7 \%$ for highest temperature from only $59.4 \%$ when untreated coal was gasified. Kinetic analysis has shown that presence of green liquor in fuel blend increases yield both during pyrolysis and during gasification phase, possibly by allowing gasification to occur along with pyrolysis.

The activation energy calculated also shows noticeable improvement, as the energy of activation decreased for fuel blends to achieve the lowest state for GL10 blend. The experiment has proven potential that green liquor holds as a cheap catalyst, but several aspects like its influence for a wider range of fuels and influence of catalytic components already residing in ashes on final process performance still needs to be addressed for a clearer image of its versatility as a fuel additive. 
Acknowledgements: This paper was prepared thanks to funding from Faculty of Energy and Fuels at the AGH University of Science and Technology as part for Ph.D. Students Grants 2016, No. 15.11.210.341.

\section{References}

1. M. Mondragon, A. Mondragon, F. Mondragon, Fuel 77(15) 1831-1839 (1998)

2. K. Jayaraman, I. Gokalp, Fuel 153, 320-327 (2015)

3. C. Li, J. Zhao, Y.Fang, Y. Wang, Front. of Chem. Eng. in Cn. 4(4), 385-393 (2010)

4. D.J. Marchand, E. Schneider, B.P. Williams, Y.L. Joo, J. Kim, G.T. Kim, S.H. Kim, Fuel Process Technol. 130, 292-298 (2015)

5. A. G. Collot, Int. J. Of Coal Geo. 65(3), 191-212.

6. F. Huhn, J. Klein, H. Jüntgen, Fuel 62(2), 196-199 (1983)

7. W.W. Li, K.Z. Li, X. Qu, R. Zhang, J.C. Bi. Fuel Proc. Tech. 126, 504-512 (2014)

8. A. Sharma, T. Takanohashi, K. Morishita, T. Takarada, Fuel 87, 491-497 (2008)

9. X. Qi, X. Guo, L. Xue, C. Zheng, C. J. Anal. Appl. Pyrol. 110, 401-407 (2014)

10. K. Otto, M. Shelef, Carbon 15(5), 317-325 (1977)

11. J. Tang J. Wang, Fuel Process. Technol. 142, 34-41 (2016)

12. D. W. McKee, Carbon, 17, 419-425 (1979)

13. Z.L. Liu, H.H. Zhu, Fuel 65(10), 1334-1338 (1986)

14. C.L. Spiro, D.W. McKee, P.G. Kosky, E.J. Lamby, Fuel 63(5), 686-691 (1984)

15. J. Kopysciński, R. Rahman R. Gupta, C. Mims, J. Hill, Fuel 117, 1181-1189 (2014)

16. M. K.Misra, K. W Ragland, A. J. Baker, Biom. and Bioen. 4(2) (1993)

17. M. Mahmoudkhani, D. W. Keith, Int. J. of Gre. Gas Cont. 3(4) (2009)

18. Polish Norm: PN G-04571:1998 Solid Fuels - Determination Of Carbon, Hydrogen And Nitrogen Contents Using The Automatic Analyzers - Macro Method

19. Polish Norm: PN G-04584:2001 Solid Fuels - Determination Of Total Sulphur And Of Ash Sulphur Content With The Use Of The Automatic Analysers

20. Polish Norm: PN-81-G-04513 Solid Fuels - Determination of lower and higher heat of combustion

21. PN-EN 14918:2010 Solid Biofuels - Determination of net calorific value

22. M.Karczewski, M. Marczak, P. Burmistrz, D. Makowska, Corrosive components of nutshells and their chars, E3S W. Of Conf. 10, 00113 (2016)

23. S. Porada, A. Rozwadowski, K. Zubek, Studies of catalytic coal gasification with steam. Polish Journal of Chemical Technology, 18(3), 97-102 (2016).

24. K. Zubek, G. Czerski and S. Porada, E3S W. of Conf. 2017 (To be published)

25. S. Porada, A. Rozwadowski, Przem. Chem. 93, (2014)

26. S. Porada, G. Czerski, T. Dziok, P. Grzywacz, D. Makowska, Fuel Proc. Tech. 130, (2015) 